\title{
Distribution and effects of ionic titanium application on energy partitioning and quantum yield of soybean under different light conditions
}

\author{
S. HUSSAIN ${ }^{*,}$, N. IQBAL ${ }^{*, \dagger}$, M.A. RAZA*, M.N. KHAN ${ }^{* *}$, S. AHMED*, T. RAHMAN ${ }^{* * *}$, P. CHEN*, \\ X. WANG ${ }^{*}, \mathrm{X} . \mathrm{DU}^{\#}, \mathrm{~W} . \mathrm{LIU}^{*,+}$, and W. YANG ${ }^{*+}$
}

Institute of Ecological Agriculture, Sichuan Agricultural University, 211-Huimin Road, Wenjiang District, Chengdu 611130, China*

Soil Survey of Punjab, Multan Road, Lahore, Pakistan**

College of Agriculture, Bahadur Sub Campus Layyah, Bahauddin Zakariya University, Multan, Pakistan ${ }^{* *}$

Department of Environmental Sciences, Hazara University, Mansehra, Pakistan ${ }^{* * *}$

Sichuan Haocheng Agricultural Science Limited Company, China ${ }^{\#}$

\begin{abstract}
Soybean growth and development response to ionic titanium application have never been investigated. Therefore, such study is needed to better explain the titanium (Ti) application for soybean crop. For the first time, we studied the effects of application of two Ti concentrations $\left(12.5\right.$ and $\left.25 \mathrm{mg} \mathrm{L}^{-1}\right)$ on photosynthetic and chlorophyll (Chl) fluorescence parameters of soybean under normal light (NL) and shade conditions (SC). Compared to NL, SC significantly decreased Chl contents, leaf area (LA), leaf thickness (LT), plant dry mater (PDM), photosynthetic and Chl fluorescence parameters, total soluble sugar, and Ti uptake. Overall, Ti application $\left(12.5 \mathrm{mg} \mathrm{L}^{-1}\right)$ had more distinct effects on LA, LT, PDM, Chl content and Chl fluorescence parameters. In conclusion, these results implied that an appropriate Ti content can improve plant morphological and anatomical features by enhancing the photosynthetic characteristics, especially under shade conditions.
\end{abstract}

Additional key words: anatomical structure; biomass; foliar application; Glycine max; photosynthesis; titanium uptake.

\section{Introduction}

Titanium (Ti) is the ninth most abundant element in the Earth's crust and makes up about $0.25 \%$ by moles and $0.57 \%$ by mass of the crust (Buettner et al. 2012). Its content in the soil is approximately $1-20 \mathrm{~g} \mathrm{~kg}^{-1}$ and the average is $6.8 \mathrm{~g} \mathrm{~kg}^{-1}$ (Zhang et al. 2012). Ti is the second most abundant transition metal, after Fe, and the elemental abundance of $\mathrm{Ti}$ is about five times lower than that of $\mathrm{Fe}$ and 100 times greater than that of $\mathrm{Cu}$. Some studies have shown that $\mathrm{Ti}$ is a beneficial element for plant growth (Lyu et al. 2017) and in recent years, Ti is used as micronutrient in the agriculture. It can enhance the growth and yield of crops and seedlings about $10-20 \%$ (Feizi et al. 2013) and can increase the quality of fruits by enhancing their contents of protein, soluble sugar, and vitamin C. It increases crop physical strength and resistance to pesticide residue, drought, freezing, heat, and disease, which ultimately improves plant's ability to acquire fertilizers (Choi et al. 2015). However, its existence in an insoluble stable state $\left(\mathrm{TiO}_{2}\right)$ makes the use of $\mathrm{Ti}$ difficult and only small amount is absorbed by plants (Lyu et al. 2017). Ti salt solution is highly unstable and can only exist at high acidity. In order to increase its absorption by plants, it is necessary to provide soluble, non-sedimentary, and longterm stable Ti. Zhang et al. (2012) invented a continuous method and production device for producing hydrolysisresistant stable ionic $\mathrm{Ti}\left(\mathrm{Ti}^{4+}\right)$ which makes $\mathrm{Ti}^{4+}$ existing in a salts solution soluble, long-term stable, and nonsedimentary, so it could be easily absorbed by plants. However, to the best of our knowledge, there is no report about its physiological activities in plants. In addition, by

\footnotetext{
$\overline{\text { Received }} 2$ January 2018, accepted 14 November 2018.

${ }^{+}$Corresponding author; phone:+86-28-86290960, fax: +86-28-86290870, e-mail: mssiyangwy@sicau.edu.cn

Abbreviations: $\mathrm{Chl}$ - chlorophyll; $C_{\mathrm{i}}$ - intercellular $\mathrm{CO}_{2}$ concentration; $E$ - transpiration rate; $g_{\mathrm{s}}-$ stomatal conductance; $\mathrm{LA}$ - leaf area; LDM - leaf dry matter; LT - leaf thickness; NL - normal light; PDM - plant dry matter; $P_{\mathrm{N}}$ - net photosynthetic rate; $\mathrm{q}_{\mathrm{p}}-$ coefficient of photochemical quenching; SC - shade condition; TiL - titanium in leaves; TiR - titanium in roots; TiS - titanium in stem; TSS - total soluble sugar; TTi - total titanium accumulation; $\Phi_{(f, D)}$ - quantum yield of constitutive nonregulatory nonphotochemical quenching; $\Phi_{(\mathrm{NPQ})}$ - quantum yield of light-induced regulatory nonphotochemical quenching; $\Phi_{(\mathrm{P})}$ - effective quantum yield of PSII; $\Phi_{(\mathrm{PSII})}$ - maximum quantum yield of PSII photochemistry.

Acknowledgements: This work was funded by the National Key Research and Development Program of China (2018YFD1000905) and the National Natural Science Foundation of China (31671626 and 31201170).

these authors contributed equally.
} 
selecting the appropriate genotypes and nutrient contents, crop yield and quality could be increased under stress conditions (Raza et al. 2018).

Shade stress is one of common abiotic stresses, and plant suffers from it when grown in high density, greenhouse, intercropping, and agroforestry systems. Furthermore, air pollution, haze, and decreasing solar radiation lead to lesser PAR (Fu et al. 2015). Plants decrease net photosynthetic rate $\left(P_{\mathrm{N}}\right)$ and optimize the agronomic traits in order to cope with poor quality and quantity of light under shade stress. Shade influences plant life in multi-faceted ways, creating new and variable environmental settings. Shade has detrimental impacts on plant growth, such as a decrease in biomass, leaf area and thickness, stem diameter (Wu et al. 2017), and ultimately yield. In maize soybean intercropping, shade of maize limits photosynthesis and is considered as a major threat to soybean growth (Su et al. 2014). Recent studies have shown that shade blocks the energy transport from PSII to PSI, reduces leaf thickness, palisade and spongy tissues, and results in lower photosynthetic capacity (Wu et al. 2017, Yao et al. 2017). In case of tropical pastures, shade reduces the root growth and net assimilation rate (Ludlow et al. 2017). Furthermore, high planting density disrupts the photosynthesis by destroying chloroplasts and thylakoid structure of plant leaf (Ren et al. 2017).

To overcome shade stress, several practices have been suggested to optimize the plant growth and photosynthesis, such as the use of shade-tolerant cultivars (Menglu et al. 2016), plant growth regulators (Yan et al. 2015), and an appropriate $\mathrm{NH}^{4+}: \mathrm{NO}_{3}^{-}$ratios (Hu et al. 2017). However, the role of ionic $\mathrm{Ti}$ in plant biology, specifically, under shade stress, has not been investigated. Therefore, the current study was aimed to gain more understanding of the role of Ti in soybean. The objectives of this study were: 1) to investigate morphological and anatomical changes in soybean leaves; 2) to explore the changes in chloroplast structure, $P_{\mathrm{N}}$, and Chl fluorescence parameters by Ti under light and shade conditions.

\section{Materials and methods}

Titanium ion solution characterization: Titanium, which has an atomic number 22 and atomic mass 47.88, is a transition element belonging to Group 4 (IVB) in the middle of the periodical table. Ti occurs at oxidation states of $\mathrm{Ti}^{2+}, \mathrm{Ti}^{3+}$ (titanous), and $\mathrm{Ti}^{4+}$ (titanic), of which $\mathrm{Ti}^{2+}$ and $\mathrm{Ti}^{3+}$ are unstable, while $\mathrm{Ti}^{4+}$ is the most stable ion. In this experiment, we used ionic titanium $\left(\mathrm{Ti}^{4+}\right)$, which was provided by Taigu Science and Technology Ltd. (Tianjing, China). The concentration was $3.5 \mathrm{~g}(\mathrm{Ti}) \mathrm{L}^{-1}$.

Plant growth, exposure, and experimental conditions: Soybean (Glycine max L.), cv. Nandou 032-4, was used in this study. The experiment was conducted in a greenhouse of Sichuan Agricultural University $\left(29^{\circ} 59^{\prime} \mathrm{N}, 103^{\circ} 00^{\prime} \mathrm{E}\right)$. Seeds were first sterilized with $0.5 \%$ sodium hypochlorite solution for $15 \mathrm{~min}$, and then germinated in the dark for $4 \mathrm{~d}$ in two plastic boxes. Seedlings were cultured hydroponically in full strength Hoagland nutrient solution in a growth chamber characterized by a $12-\mathrm{h}$ dark/12-h light photoperiod, $28^{\circ} \mathrm{C}$ day $/ 25^{\circ} \mathrm{C}$ night temperature, and approximately $60 \%$ relative humidity. When the first trifoliate leaf developed, the seedlings were transferred to shade and light conditions and different Ti treatments were applied. Following concentrations of $\mathrm{Ti}$ solution were used: $0,12.5$, and $25 \mathrm{mg} \mathrm{L}^{-1}$, named as $\mathrm{T}_{0}, \mathrm{~T}_{1}$, and $\mathrm{T}_{2}$, respectively. The Ti was sprayed two times with the $7-d$ interval after emergence. Each treatment was replicated three times. Seedlings were allowed to grow for $30 \mathrm{~d}$.

Light environment: Shade condition (SC) was provided by one layer of green filters ( $Q-M A X 122$, Hampshire, UK) as $27 \%$ of full sunlight. The R:FR ratio under shade was (0.5-0.6). Normal light (NL) condition was provided by simply placing the pots in the growth chamber without the shade net.

Leaf area (LA) and leaf thickness (LT): Leaf area was measured by using (CI-203 CID, Bio-Science Portable Instruments for Precision Plant Measurement Inc., WA, USA). Leaf thickness was measured by using Image $J 2 x$ $1.42 q$.

Plant dry matter (PDM): Plants were sampled from each replicate for morphological analysis; stem and aboveground biomass were measured. All aboveground parts of soybean plants were exposed to $105^{\circ} \mathrm{C}$ for $1 \mathrm{~h}$ and dried to constant mass at $75^{\circ} \mathrm{C}$ to determine the biomass of the stems and leaves.

Photosynthetic characteristics and Chl content: The net photosynthetic rate $\left(P_{\mathrm{N}}\right)$, stomatal conductance $\left(g_{\mathrm{s}}\right)$, intercellular $\mathrm{CO}_{2}\left(C_{\mathrm{i}}\right)$, and transpiration $(E)$ were measured with a portable photosynthesis system (Model LI-6400, LI-COR Inc., Lincoln, NE). SPAD-502 (Minolta, Japan) apparatus was used for the measurement of leaf Chl content. Latest fully expanded leaves were selected to measure photosynthetic parameters on plants between 08:00 and 11:00 h using following settings: $\mathrm{PAR}_{\mathrm{i}}=1,000$ $\mu \mathrm{mol}$ (photon) $\mathrm{m}^{-2} \mathrm{~s}^{-1}$, stomatal ratio $=0.5$, flow $=500$

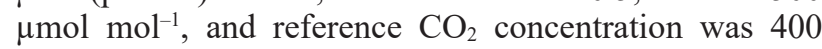
$\mu \mathrm{mol} \mathrm{mol}{ }^{-1}$. Physiological measurements were taken when $P_{\mathrm{N}}, g_{\mathrm{s}}$, and fluorescence were stable $\left(P_{\mathrm{N}}\right.$ : slope $<1$ and $g_{\mathrm{s}}$ : slope $<0.05$ for $45 \mathrm{~s}$ ).

Chl fluorescence parameters: Chl fluorescence technology (FluorImager software, Technologia LTD version 2.2.2.2) was used to investigate soybean response to ionic Ti both under light and shade conditions. We calculated: 1) effective quantum yield of PSII, $\left.\Phi_{(\mathrm{P})} ; 2\right)$ quantum yield of light-induced regulatory nonphotochemical quenching, $\Phi_{(\mathrm{NPQ})}$; 3) quantum yield of constitutive nonregulatory nonphotochemical quenching, $\Phi_{(\mathrm{f}, \mathrm{D})}$; 4) coefficient of photochemical quenching, $\mathrm{q}_{\mathrm{P}}$; and 5) quantum yield of PSII photochemistry, $\Phi_{(\mathrm{PSII})}$, according to Humplík et al. (2015) and Lazár (2015).

Total soluble sugar (TSS) content was measured with 
anthrone colorimetric reagents method (Wu et al. 2017). Powder [0.1 g (DM)] of well-ground leaves was put into a $10-\mathrm{mL}$ centrifuge tube with $10 \mathrm{~mL}$ of $80 \%$ ethanol. The tube was incubated in a water bath of $80^{\circ} \mathrm{C}$ for $30 \mathrm{~min}$, and then centrifuged $(3,000 \times g, 15 \mathrm{~min})$. The residue was extracted again twice using $80 \%$ ethanol. The three supernatants were combined and mixed. One $\mathrm{mL}$ of supernatant and one $\mathrm{mL}$ of distilled water were added into $10-\mathrm{mL}$ test tube. Anthrone reagent $(0.2 \%)$ of $4 \mathrm{~mL}$ was mixed with concentrated $\mathrm{H}_{2} \mathrm{SO}_{4}$ in a test tube and placed in boiling water bath for $15 \mathrm{~min}$. After cooling, the absorbance was read at $620 \mathrm{~nm}$ with spectrophotometer (MAPADA V1100D, Shanghai, China) and soluble sugar content was calculated as: Total soluble sugar $=($ standard curve value $\times$ dilution ratio)/sample mass. The results were expressed as $\mathrm{mg} \mathrm{g}^{-1}(\mathrm{DM})$.

Anatomical structure of leaves: The samples for anatomical structure of soybean leaves were taken after one month of treatment. Leaf segments $(5 \times 5 \mathrm{~mm})$ without major veins were cut from each middle leaflet of three latest fully expanded leaves with a surgical scissors. The segments were fixed in a formaldehyde (FAA) solution (38\% FAA/glacial acetic acid/70\% alcohol, 5:5:90, $\mathrm{v} / \mathrm{v} / \mathrm{v}$ ) at $4^{\circ} \mathrm{C}$. The fixed segments were dehydrated in a graded alcohol and $n$-butyl alcohol series, embedded in paraffin, and cut by rotary microtome (RM2235, Leica Microsystems Ltd., Germany) at thickness of $10 \mu \mathrm{m}$. Light microscopy (Nikon Eclipse50i, Japan) was carried out with a $10-\mu \mathrm{m}$ thick transverse section of the leaf stained with $0.5 \%$ safranine solution.

Chloroplast ultrastructure: The segments $(0.5 \times 0.5 \mathrm{~cm})$ of soybean leaves were prefixed with a mixed solution of $3 \%$ glutaraldehyde, then the segments were post-fixed in $1 \%$ osmium tetroxide, dehydrated in acetone series, infiltrated, and embedded in Epox 812. The semi-thin sections were stained with methylene blue and ultrathin sections were cut with diamond knife, stained with uranyl acetate and lead citrate. Sections were examined with a transmission electron microscope (H-600IV, Hitachi, Japan).

Elemental analyses were performed to investigate $\mathrm{Ti}$ mobilization and accumulation in soybean plants. The concentration of $\mathrm{Ti}$ in the roots, stem, and leaves were analyzed by an inductively coupled plasma emission spectrometer (ICP-OES/ICP-MS, Aurora M90, Bruker, Bremen, Germany). The plant samples were dried, weighed $(0.1 \mathrm{~g})$, placed in a glass vial, and then digested by $2 \mathrm{ml}$ of $\mathrm{HNO}_{3}$ and $0.5 \mathrm{~mL}$ of $\mathrm{H}_{2} \mathrm{O}_{2}$ at a temperature of $150^{\circ} \mathrm{C}$ until the solution turned whitish; the solution was then evaporated and reduced to $1 \mathrm{ml}$. The digested samples were diluted by $10 \mathrm{~mL}$ of $2 \%$ nitric acid and then filtered through $0.2-\mu \mathrm{m}$ nylon filter, followed by $0.02-\mu \mathrm{m}$ membrane filter paper. The final filtered solution was diluted three times before analysis by ICP-MS. The results were expressed as $\mathrm{mg} \mathrm{kg}^{-1}$.

Statistical analysis: All the data recorded for every trait were analyzed using Statistix 8.1. An analysis of variance (ANOVA) was used to determine the treatment effects on the measured variables. The least significance difference (LSD) test was performed to compare means at 5\% probability level. OriginPro 8.0 was used for the graphical presentation of the data.

\section{Results}

Leaf area (LA) and leaf thickness (LT): In our study, the highest LA $\left(56.7 \mathrm{~cm}^{2}\right)$ and LT $(208.6 \mu \mathrm{m})$ were measured under NL, while the lowest LA $\left(29.6 \mathrm{~cm}^{2}\right)$ and LT $(131.8 \mu \mathrm{m})$ were found under SC under control conditions. The Ti application had a considerable effect on LA and LT, as did the light and shade conditions. LA and LT of $\mathrm{T}_{1}$ treatment significantly increased and the maximum LA $\left(73.9 \mathrm{~cm}^{2}\right)$ and LT $(411.2 \mu \mathrm{m})$ were obtained, The interactive effect showed that under $\mathrm{NL}$ and $\mathrm{SC}, \mathrm{T}_{1}$ treatment had the highest leaf area of $73.9 \mathrm{~cm}^{2}$ and 38.5 $\mathrm{cm}^{2}$. Interactive effects of $\mathrm{Ti}$ concentrations and light conditions for LA and LT were found to be significant (Fig. 1A,B). Overall, the $\mathrm{T}_{1}$ increased LA and LT by 27 and $70 \%$, respectively, compared with control treatment. In addition, anatomical structure of leaf revealed that $\mathrm{Ti}$ significantly affected the leaf thickness under NL and SC (Fig. 2).

Dry matter (DM): The Ti application and different light conditions showed a significant effect on plant and leaf dry matter (DM) accumulation. Similarly, different light conditions changed the pattern of DM distribution between leaves and stem. The maximum ( $0.9 \mathrm{~g}$ per plant) leaf dry matter (LDM) and (1.3 g per plant) plant dry matter (PDM) were noted under NL, whereas minimum (0.3 g per plant) LDM and ( $0.5 \mathrm{~g}$ per plant) PDM were measured under SC. However, LDM and PDM increased as the Ti content increased from $\mathrm{T}_{0}$ to $\mathrm{T}_{2}$. In NL, the highest LDM (1 g per plant) and PDM were noticed under treatment $\mathrm{T}_{2}$, whereas the lowest LDM (0.5 g per plant) and PDM ( 0.8 g per plant) were recorded in $\mathrm{T}_{0}$ treatment. Interactive results for different light conditions and Ti concentrations were found significant (Fig. 1C,D). On average, LDM and PDM increased by 31 and $29 \%$ in $\mathrm{T}_{2}$ than $\mathrm{T}_{0}$ treatment, respectively, suggesting that $\mathrm{LDM}$ and $\mathrm{PDM}$ were directly proportional with the increase in the leaf size.

Chl content: In this experiment, light conditions caused significant differences in $\mathrm{Chl}$ contents. As shown in Table 1, Chl content of soybean leaves in NL (30.4) was significantly higher than those of SC (26.1). Additionally, the Chl content significantly increased with the increase in $\mathrm{Ti}$ contents. The highest (31.2) and the lowest (24.5) Chl content was determined in treatment $T_{2}$ and $T_{0}$, respectively. The interactive effect of Ti concentrations and different light conditions was found significant. Relative to control treatment $\left(\mathrm{T}_{0}\right)$, soybean plants under $\mathrm{T}_{2}$ reached $27 \%$ higher $\mathrm{Chl}$ content.

Photosynthetic characteristics: Different light conditions and $\mathrm{Ti}$ concentrations showed a significant impact 


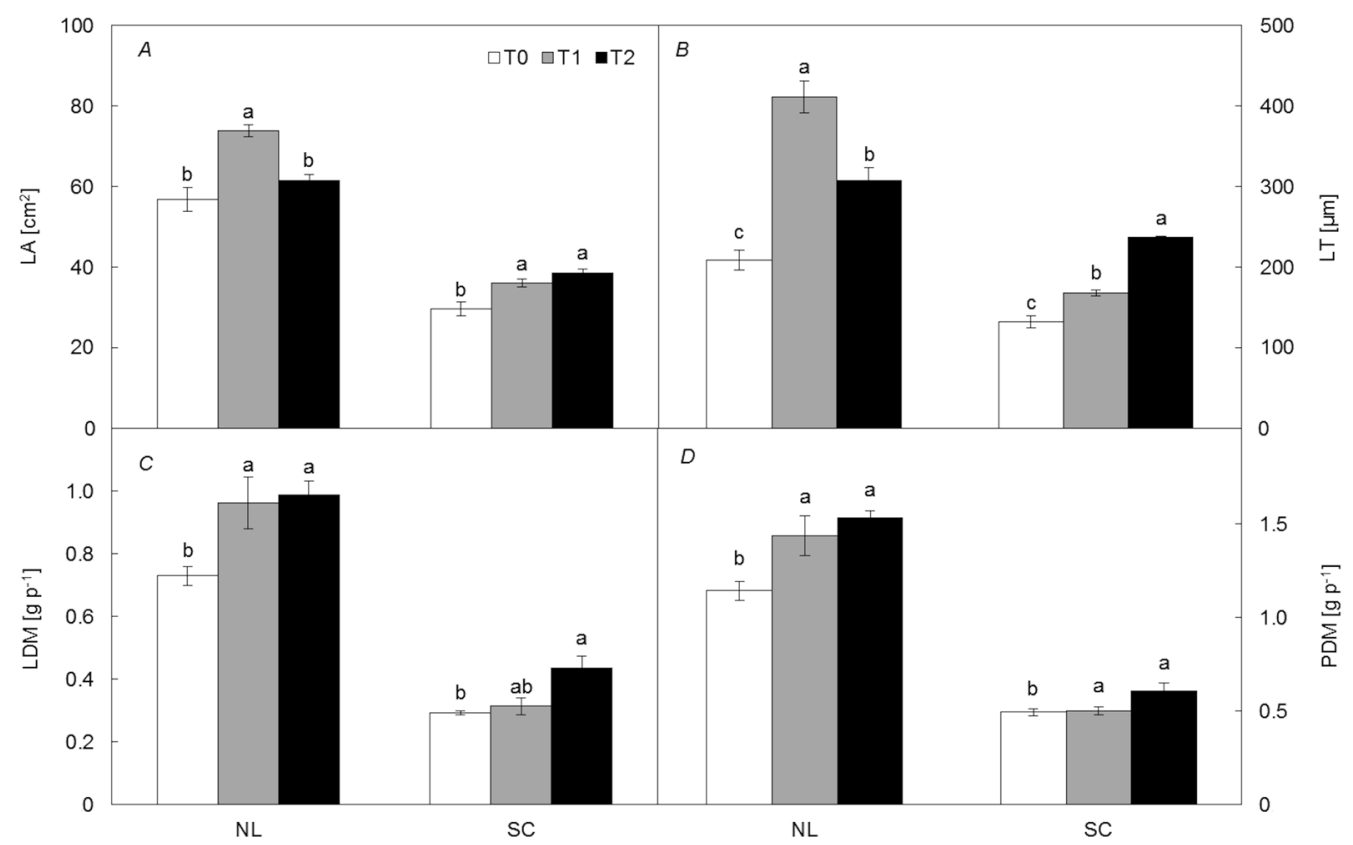

Fig. 1. Effect of titanium (Ti) on aerial parts of soybean seedlings under normal light (NL) and shade conditions (SC). $\mathrm{T}_{0}, \mathrm{~T}_{1}$, and $\mathrm{T}_{2}$ refer to $0,12.5$, and $25 \mathrm{mg}(\mathrm{Ti}) \mathrm{L}^{-1}$, respectively. $(A)$ leaf area (LA); $(B)$ leaf thickness $(\mathrm{LT}) ;(C)$ leaf dry mass $(\mathrm{LDM})$; and $(D)$ plant dry mass $(\mathrm{PDM})$. Values are means $\pm \mathrm{SE}, n=3$. Different lowercase letters indicate a significant difference $(p<0.05)$ between treatments.

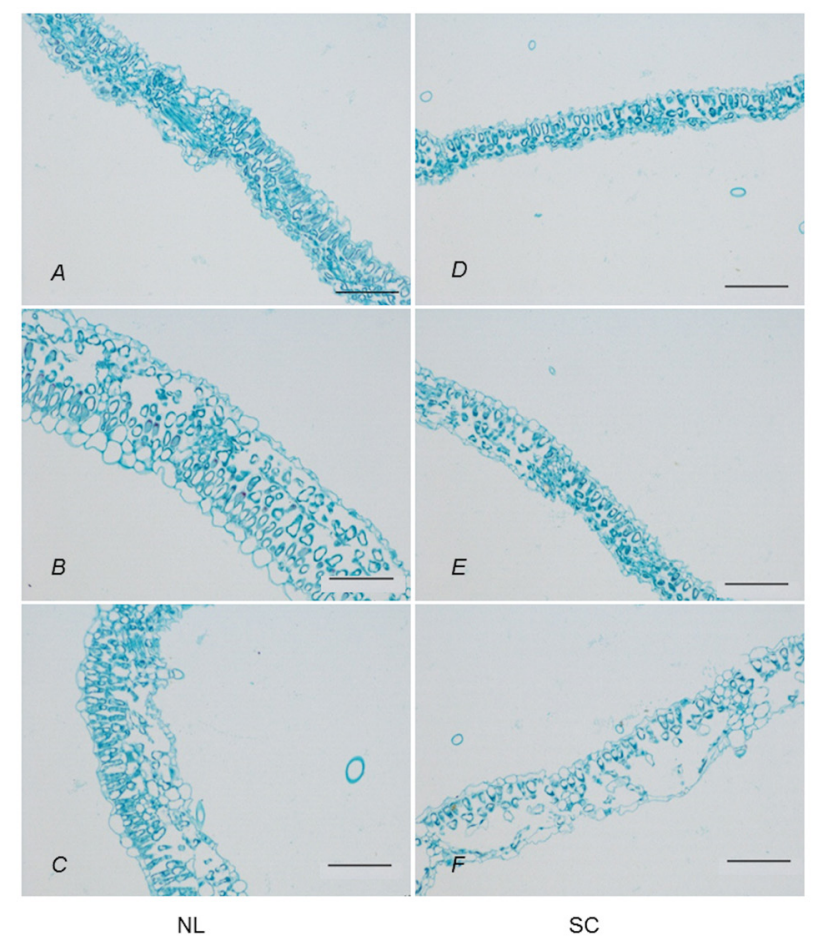

Fig. 2. Leaf anatomy of soybean plants under normal light (NL) $(A-C)$ and shaded conditions (SC) $(D-F)$ treated with $0 \mathrm{mg}(\mathrm{Ti})$ $\mathrm{L}^{-1}\left(\mathrm{~T}_{0}\right)(A, D) ; 12,5 \mathrm{mg}(\mathrm{Ti}) \mathrm{L}^{-1}\left(\mathrm{~T}_{1}\right)(B, E)$; and $25 \mathrm{mg}(\mathrm{Ti}) \mathrm{L}^{-1}\left(\mathrm{~T}_{2}\right)$ $(C, F)$. Bars indicate $100 \mu \mathrm{m}$ in length. on photosynthetic parameters $\left(P_{\mathrm{N}}, E, g_{\mathrm{s}}\right.$, and $\left.C_{\mathrm{i}}\right)$. The maximum $P_{\mathrm{N}}\left[14.3 \mu \mathrm{mol}\left(\mathrm{CO}_{2}\right) \mathrm{m}^{-2} \mathrm{~s}^{-1}\right], E\left[3.9 \mathrm{mmol}\left(\mathrm{H}_{2} \mathrm{O}\right)\right.$ $\left.\mathrm{m}^{-2} \mathrm{~s}^{-1}\right]$, and $g_{\mathrm{s}}\left[0.19 \mathrm{~mol}\left(\mathrm{H}_{2} \mathrm{O}\right) \mathrm{m}^{-2} \mathrm{~s}^{-1}\right]$ were recorded under NL compared to the values under $\mathrm{SC}$, where following values were measured: $P_{\mathrm{N}}$ of $10.3 \mu \mathrm{mol}\left(\mathrm{CO}_{2}\right) \mathrm{m}^{-2} \mathrm{~s}^{-1}, E$ of $2.9 \mathrm{mmol}\left(\mathrm{H}_{2} \mathrm{O}\right) \mathrm{m}^{-2} \mathrm{~s}^{-1}, g_{\mathrm{s}}$ of $0.10 \mathrm{~mol}\left(\mathrm{H}_{2} \mathrm{O}\right) \mathrm{m}^{-2} \mathrm{~s}^{-1}$, and $C_{\mathrm{i}} 297.6 \mu \mathrm{mol}\left(\mathrm{CO}_{2}\right) \mathrm{mol}^{-1}$. Ti application significantly increased the $P_{\mathrm{N}}, g_{\mathrm{s}}$, and $E$, and the highest $P_{\mathrm{N}}(14.4), g_{\mathrm{s}}$ (0.2), and $E$ (3.6) were recorded under $\mathrm{T}_{2}$, while the lowest $P_{\mathrm{N}}(10.1)$ and $E$ (3.3) were noticed in control $\left(\mathrm{T}_{0}\right)$, and the lowest $g_{\mathrm{s}}(0.1)$ was noticed in $\mathrm{T}_{1}$ treatment. On the contrary, Ti application significantly decreased the $C_{\mathrm{i}}$ of soybean plants, maximum (320.8) and minimum (271.0) $C_{\mathrm{i}}$ was noticed under $\mathrm{T}_{0}$ and $\mathrm{T}_{2}$ treatment, respectively. Interactive effect of $\mathrm{Ti}$ concentrations and different light conditions was found significant for all photosynthetic parameters (Table 1). Overall, treatment $\mathrm{T}_{2}$ increased $P_{\mathrm{N}}$ by $42 \%$ compared to $\mathrm{T}_{0}$, suggesting that $P_{\mathrm{N}}$ increased as the LA and Chl content increased by Ti application.

Chl fluorescence parameters: In our experiment, the Chl fluorescence was changed significantly during the experimental period in response to $\mathrm{Ti}$ application and different light conditions. There was not a significant difference for $\Phi_{(\mathrm{PSII})}$ under both light conditions. However, Ti application significantly enhanced $\Phi_{(\mathrm{PSII})}$ in $\mathrm{T}_{2}$ treatment under SC, where the maximum $\Phi_{(\mathrm{PSI})}$ was recorded (Fig. 3A). Different light conditions and Ti application considerably affected $\Phi_{(\mathrm{P})}, \Phi_{(\mathrm{f}, \mathrm{D})}, \Phi_{(\mathrm{NPQ})}$, and $\mathrm{q}_{\mathrm{p}}$. Compared with SC, the $\Phi_{(\mathrm{P})}, \Phi_{(\mathrm{f}, \mathrm{D})}, \Phi_{(\mathrm{NPQ})}$, and $\mathrm{q}_{\mathrm{p}}$ under $\mathrm{NL}$ were higher by $32,13,10$, and $16 \%$, respectively (Fig. $3 B-E$ ). Similarly, under NL, Ti application significantly increased 
Table 1. Effect of Ti application on Chl content and photosynthetic parameters of soybean plants under normal light (NL) and shade conditions (SC). $\mathrm{T}_{0}, \mathrm{~T}_{1}$, and $\mathrm{T}_{2}$ refer to $0,12.5$, and $25 \mathrm{mg}(\mathrm{Ti}) \mathrm{L}^{-1}$, respectively. Data are means, $n=3$. Values which do not share the same letters in the column differ significantly at $p \leq 0.05 . P_{\mathrm{N}}-$ net photosynthetic rate, $\mathrm{g}_{\mathrm{s}}-$ stomatal conductance, $C_{\mathrm{i}}-$ intercellular $\mathrm{CO}_{2}$ concentration, $E$ - net transpiration rate, ${ }^{*}$ - significant.

\begin{tabular}{|c|c|c|c|c|c|}
\hline $\begin{array}{l}\text { Environmental } \\
\text { conditions }(\mathrm{Ec})\end{array}$ & Chl (SPAD value) & $P_{\mathrm{N}}\left[\mu \mathrm{mol}\left(\mathrm{CO}_{2}\right) \mathrm{m}^{-2} \mathrm{~s}^{-1}\right]$ & $g_{\mathrm{s}}\left[\mathrm{mol}\left(\mathrm{H}_{2} \mathrm{O}\right) \mathrm{m}^{-2} \mathrm{~s}^{-1}\right]$ & $C_{\mathrm{i}}\left[\mu \mathrm{mol}\left(\mathrm{CO}_{2}\right) \mathrm{mol}^{-1}\right]$ & $E\left[\mathrm{mmol}\left(\mathrm{H}_{2} \mathrm{O}\right) \mathrm{m}^{-2} \mathrm{~s}^{-1}\right]$ \\
\hline NL & $30.417^{\mathrm{a}}$ & $14.258^{\mathrm{a}}$ & $0.1917^{\mathrm{a}}$ & $278.58^{b}$ & $3.9833^{\mathrm{a}}$ \\
\hline $\mathrm{SC}$ & $26.100^{\mathrm{b}}$ & $10.355^{\mathrm{b}}$ & $0.1031^{\mathrm{b}}$ & $297.67^{\mathrm{a}}$ & $2.9575^{\mathrm{b}}$ \\
\hline $\operatorname{LSD}(0.05)$ & 1.4606 & 0.3166 & 0.0363 & 13.259 & 0.2200 \\
\hline \multicolumn{6}{|l|}{ Treatment } \\
\hline $\mathrm{T}_{0}$ & $24.475^{\mathrm{c}}$ & $10.145^{\mathrm{c}}$ & $0.1628^{\mathrm{a}}$ & $320.75^{\mathrm{a}}$ & $3.5513^{\mathrm{a}}$ \\
\hline $\mathrm{T}_{1}$ & $29.100^{\mathrm{b}}$ & $12.375^{\mathrm{b}}$ & $0.1136^{\mathrm{b}}$ & $272.63^{b}$ & $3.2625^{\mathrm{a}}$ \\
\hline $\mathrm{T}_{2}$ & $31.200^{\mathrm{a}}$ & $14.400^{\mathrm{a}}$ & $0.1658^{\mathrm{a}}$ & $271.00^{\mathrm{b}}$ & $3.5975^{\mathrm{a}}$ \\
\hline $\operatorname{LSD}(0.05)$ & 1.4167 & 0.4178 & 0.0447 & 17.127 & 0.5350 \\
\hline Interaction $(\mathrm{Ec} \times \mathrm{T})$ & $*$ & $*$ & $*$ & $*$ & $*$ \\
\hline
\end{tabular}

the $\Phi_{(\mathrm{P})}, \Phi_{(\mathrm{f}, \mathrm{D})}$, and $\mathrm{q}_{\mathrm{p}}$ of soybean plants, and the maximum of $\Phi_{(\mathrm{P})}, \Phi_{(\mathrm{f}, \mathrm{D})}$, and $\mathrm{q}_{\mathrm{p}}$ were $0.11,0.3$, and 0.45 , respectively, under $T_{1}$ treatment, while minimum $\Phi_{(\mathrm{P})}, \mathrm{q}_{\mathrm{p}}$, and $\Phi_{(\mathrm{f}, \mathrm{D})}$ were measured in $\mathrm{SC}$ (Fig. $3 B-D$ ). In addition, the highest value $(0.65)$ of $\Phi_{(\mathrm{NPQ})}$ was noted under treatment $\mathrm{T}_{2}$ and the lowest value was recorded in $\mathrm{T}_{1}$ treatment (Fig. 3E). Moreover, significant differences in Chl fluorescence parameters were noticed in the interaction of different light conditions and $\mathrm{Ti}$ concentrations. Overall, these results are indicating that changes in photosynthetic rate under different light conditions were directly associated with the changes in Chl fluorescence parameters.

Total soluble sugar (TSS): To investigate the differences in leaf TSS of soybean in response to Ti concentrations, the TSS of leaves under NL and SC for $\mathrm{T}_{0}, \mathrm{~T}_{1}$, and $\mathrm{T}_{2}$ were analyzed after seven days of $\mathrm{Ti}$ application (foliar). The different light conditions significantly affected the TSS content in soybean leaves, and the maximum TSS content (34.6 $\mathrm{mg} \mathrm{g}^{-1}$ ) was measured in leaves under NL, whereas shade significantly decreased the TSS. The TSS increased as Ti concentrations increased from $\mathrm{T}_{0}$ to $\mathrm{T}_{2}$. The maximum TSS (32.2 $\mathrm{mg} \mathrm{g}^{-1}$ ) was observed in treatment $\mathrm{T}_{2}$ and minimum TSS $\left(23.3 \mathrm{mg} \mathrm{g}^{-1}\right)$ was noticed under control treatment $\left(\mathrm{T}_{0}\right)$. Furthermore, the interaction of $\mathrm{Ti}$ concentrations and different light conditions for TSS showed significant differences (Fig. 4). On average, TSS of soybean plants under $\mathrm{T}_{2}$ increased by $38 \%$ than that of $\mathrm{T}_{0}$ treatment.

Chloroplast ultrastructure of soybean: In this study, changes in the ultrastructure of chloroplasts occurred (Fig. 5). The different light conditions and Ti concentrations significantly changed the shape, size, and number of chloroplasts. Under $\mathrm{NL}$, the leaves under $\mathrm{T}_{2}$ treatment had thicker grana $(G)$ stacks compared to $T_{1}$ and $T_{0}$ (Fig. 5C). The number of starch grains $(S)$ increased in $T_{1}$ and $T_{2}$, while the larger starch grains were observed in leaves grown under NL. Under SC, the starch grains and grana stack of $T_{0}$ were smaller in size as compared to $T_{1}$ and
$\mathrm{T}_{2}$ plants (Fig. 5D). However, $\mathrm{T}_{1}$ demonstrated more and larger starch grains as compared to $\mathrm{T}_{2}$ and $\mathrm{T}_{0}$ (Fig. 5E).

Ti accumulation and distribution in soybean: In both light conditions, the highest $\mathrm{Ti}$ accumulation was noted in soybean plants under NL, whereas it decreased sharply in SC (Fig. 6D). Differences between Ti concentrations revealed that soybean plants under $\mathrm{T}_{1}$ accumulated $30 \%$ more $\mathrm{Ti}$ than that in $\mathrm{T}_{0}$ treatment. Interestingly, relative to the shade, soybean plants under NL showed $222.6 \%$ higher $\mathrm{Ti}$ accumulation. Moreover, the distribution pattern of Ti in different plant organs is presented for all Ti treatments and different light conditions (Fig. 6A-C). Large fluctuations were observed for Ti content in leaf, stem, and roots under different light conditions. The maximum accumulation of Ti was observed in roots and stem followed by leaves. The highest Ti content in roots $\left(138.3 \mathrm{mg} \mathrm{kg}^{-1}\right)$, stem $(32.4 \mathrm{mg}$ $\mathrm{kg}^{-1}$ ), and leaf (40.9 $\mathrm{mg} \mathrm{kg}^{-1}$ ) were recorded under NL. However, under $\mathrm{SC}$, the highest $\mathrm{Ti}$ accumulation was noticed in leaf $\left(27.7 \mathrm{mg} \mathrm{kg}^{-1}\right)$, roots $\left(28.9 \mathrm{mg} \mathrm{kg}^{-1}\right)$, and stem $\left(18.7 \mathrm{mg} \mathrm{kg}^{-1}\right)$. The Ti treatments increased the stem, leaf, and root Ti content, and the highest Ti content in roots (83.9 $\left.\mathrm{mg} \mathrm{kg}^{-1}\right)$, stem $\left(25.2 \mathrm{mg} \mathrm{kg}^{-1}\right)$, and leaf $\left(34.3 \mathrm{mg} \mathrm{kg}^{-1}\right)$ was noticed under treatment $\mathrm{T}_{2}$, respectively. Relative to control $\left(\mathrm{T}_{0}\right)$, under NL, $\mathrm{T}_{2}$ treatment increased Ti content by $29.8 \%$ while under $\mathrm{SC} \mathrm{T}_{1}$ treatment increased Ti content by $85.4 \%$ (Fig. $6 D$ ).

\section{Discussion}

In multiple cropping systems, retardation of photosynthesis due to shade stress results in low agricultural productivity. Crop growth can be improved by enhancing their lightuse efficiency under shade conditions (Qu et al. 2017). In previous studies, it has been reported that the Ti application can play a favorable role in improving crop growth and seed yield by increasing the crop resistance to abiotic stress (Feizi et al. 2013, Choi et al. 2015). In current study, the effects of Ti on growth parameters of soybean plants grown under different light conditions were investigated. Leaf 


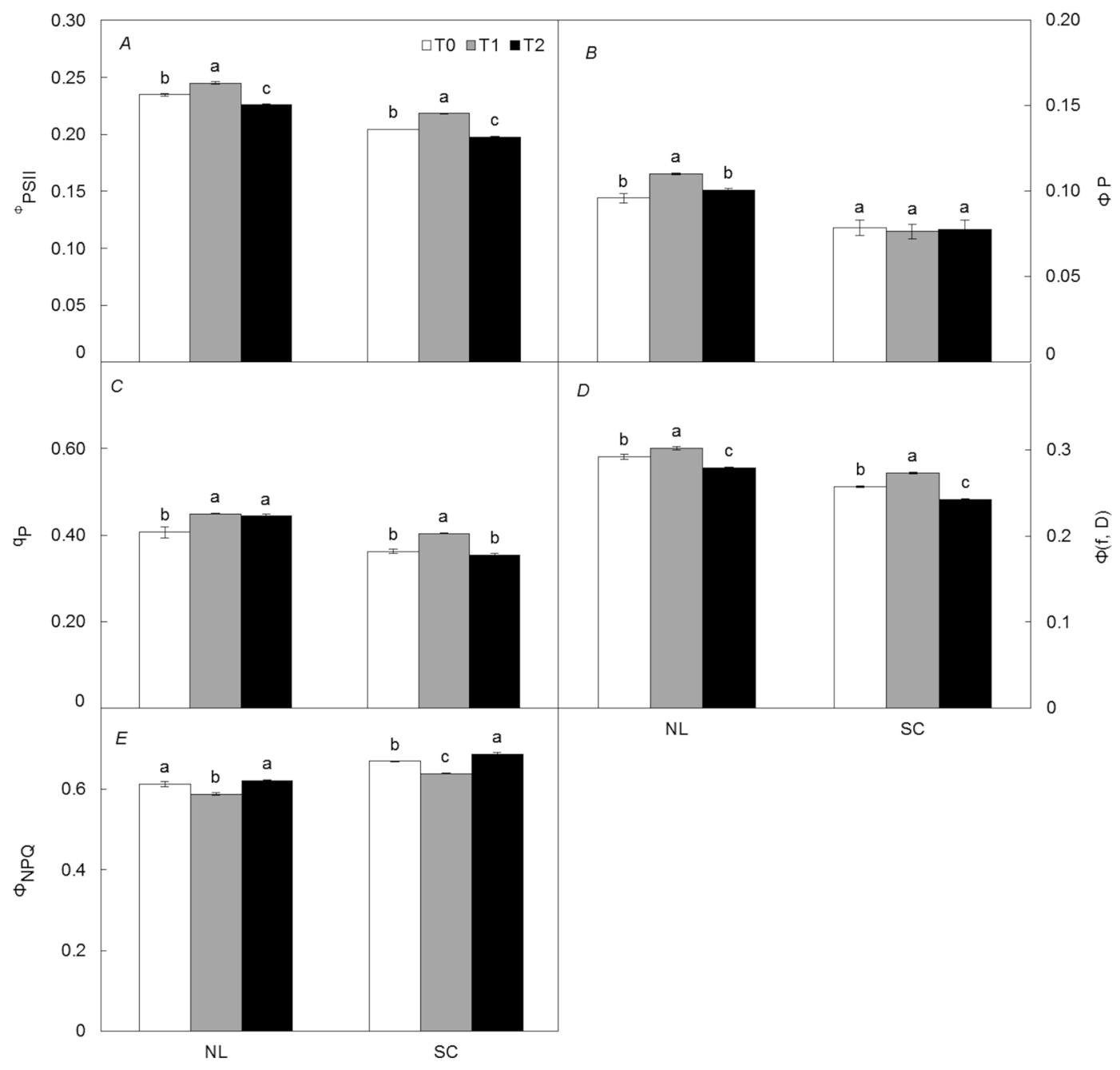

Fig. 3. Effect of titanium (Ti) on soybean chlorophyll fluorescence parameters under normal light (NL) and shade conditions (SC). $\mathrm{T}_{0}, \mathrm{~T}_{1}$, and $\mathrm{T}_{2}$ refer to $0,12.5$, and $25 \mathrm{mg}(\mathrm{Ti}) \mathrm{L}^{-1}$, respectively. Values are means $\pm \mathrm{SE}, n=3$. Different lowercase letters indicate a significant difference $(p<0.05)$ between treatments. $\Phi_{(\mathrm{PSII})}-$ maximum quantum yield of PSII photochemistry, $\Phi_{(\mathrm{P})}-$ effective quantum yield of PSII, $\mathrm{q}_{\mathrm{p}}$ - coefficient of photochemical quenching, $\Phi_{(\mathrm{f}, \mathrm{D})}$ - quantum yield of constitutive nonregulatory nonphotochemical quenching, $\Phi_{(\mathrm{NPQ})}-$ quantum yield of light induced regulatory nonphotochemical quenching.

is the main light-harvesting plant organ and its anatomy influences the photosynthetic capacity (Bielczynski et al. 2017). Similarly, it was found that Ti improved the leaf area, leaf thickness, Chl content, and total plant biomass of soybean under shade stress. Foliar application of Ti significantly improved soybean growth by mitigating the adverse effects of shade. However, Ti can induce toxicity depending on its application dosage (Ruffini Castiglione et al. 2016). A higher rate of $\mathrm{Ti}$ application suppresses the plant growth and root elongation, and is toxic (Ruffini Castiglione et al. 2011).

Furthermore, foliar application of $\mathrm{Ti}$ increased the Chl content in tomato and cucumber leaves (Servin et al. 2013, Raliya et al. 2015). In the present study, it was found that the lower concentration of Ti could improve leaf morphological characteristics. However, under stress conditions (shade), the higher concentration would be beneficial to minimize the detrimental effect of abiotic stress. Under shade conditions, improving lightuse efficiency is critical. Previous research has shown that the soybean seedlings intercropped with maize exhibited significantly downregulated $P_{\mathrm{N}} \quad(-38.3 \%)$, $E(-42.7 \%)$, and $g_{\mathrm{s}}(-55.4 \%)$ due to low available light. ( $\mathrm{Su}$ et al. 2014). In our experiment, $\mathrm{T}_{2}$ treatment significantly increased the $P_{\mathrm{N}}$ by increasing the $g_{\mathrm{s}}$ and $E$ of soybean plants as compared to the $\mathrm{T}_{0}$ (Table 1 ). The $C_{\mathrm{i}}$ decreased with the increasing content of Ti under different light conditions. These results suggested that the increase in $P_{\mathrm{N}}$ could be due to the increase in $g_{\mathrm{s}}$ after Ti application. In this study, higher $g_{\mathrm{s}}, 0.22$ and 0.14 $\mu \mathrm{mol}\left(\mathrm{H}_{2} \mathrm{O}\right) \mathrm{m}^{-2} \mathrm{~s}^{-1}$ under light and shade, respectively, indicated that the changes in $P_{\mathrm{N}}$ were closely associated with stomatal opening.

Increased photosynthetic capacity is always accompanied with high quantity of electrons passing through PSII (Yao et al. 2017). Chl fluorescence is one of the main 


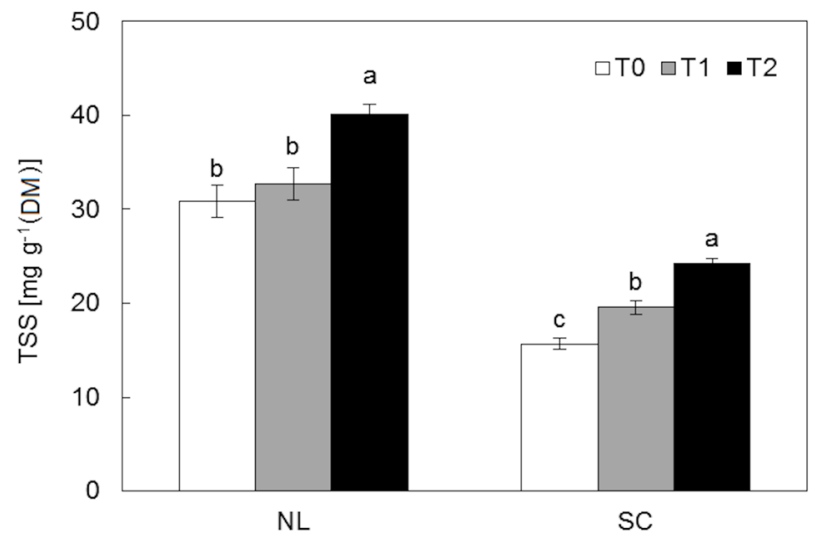

Fig. 4. Effect of titanium (Ti) on total soluble sugar (TSS) content of soybean leaves under normal light (NL) and shade conditions (SC). $\mathrm{T}_{0}, \mathrm{~T}_{1}$, and $\mathrm{T}_{2}$ refer to $0,12.5$, and $25 \mathrm{mg}(\mathrm{Ti}) \mathrm{L}^{-1}$, respectively Values are means $\pm \mathrm{SE}, n=3$. Different lowercase letters indicate a significant difference $(p<0.05)$ between treatments.

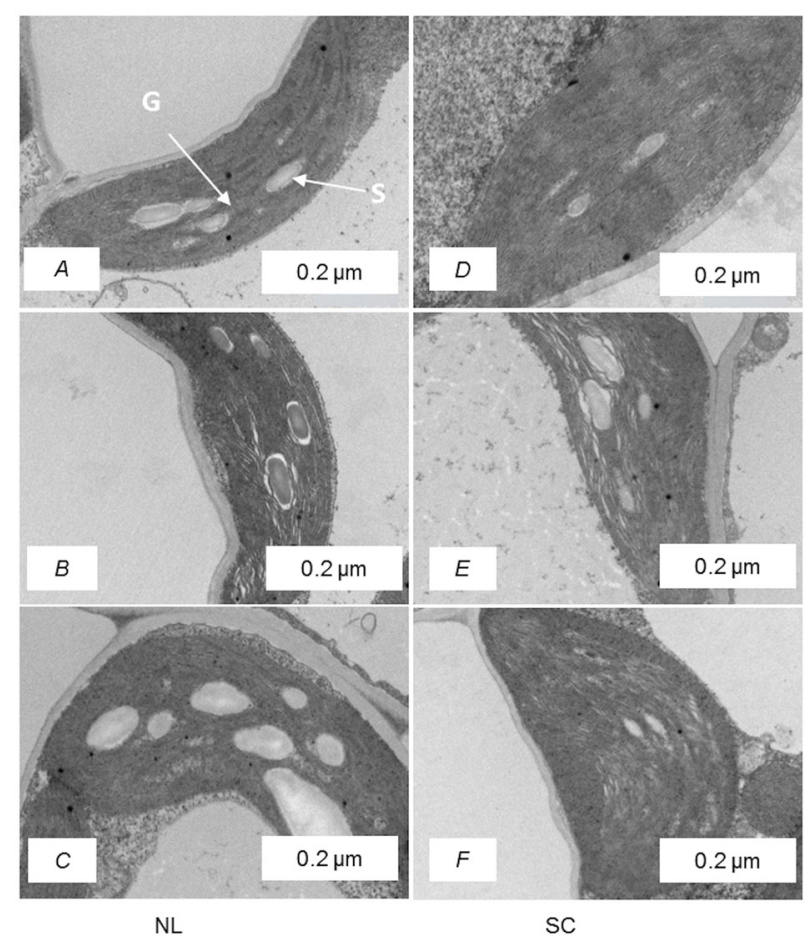

Fig. 5. Chloroplast ultrastructure of soybean under normal light (NL) $(A-C)$ and shade conditions (SC) $(D-F)$ treated with $0 \mathrm{mg}$ $\mathrm{L}^{-1}\left(\mathrm{~T}_{0}\right)(A, D) ; 12,5 \mathrm{mg}(\mathrm{Ti}) \mathrm{L}^{-1}\left(\mathrm{~T}_{1}\right)(B, E)$; and $25 \mathrm{mg}(\mathrm{Ti}) \mathrm{L}^{-1}\left(\mathrm{~T}_{2}\right)$ $(C, F) . \mathrm{G}$ - grana, $\mathrm{S}-$ starch grain.

indicators of photosynthetic regulation and plant responses to environmental conditions because of its sensitivity and convenience (Dai et al. 2009). Former studies have reported that a decrease in plant growth under SC was due to lower energy absorbed by the leaf and subsequently translocated to PSII (Huang et al. 2011, Yao et al. 2017). In present study, similar results were obtained as $\Phi_{(\mathrm{P})}$ and
$\Phi_{(f, D)}$ were significantly lower in soybean plants under SC compared to NL. Compared with $\mathrm{T}_{0}$ and $\mathrm{T}_{2}$, treatment $\mathrm{T}_{1}$ significantly increased the $\Phi_{(\mathrm{P})}, \Phi_{(\mathrm{f}, \mathrm{D})}, \mathrm{q}_{\mathrm{p}}$, and $\Phi_{(\mathrm{NPQ})}$ under SC and NL, whereas, the higher concentration of $\mathrm{Ti}\left(\mathrm{T}_{2}\right)$ decreased the $\mathrm{Chl}$ fluorescence. It reveals that $\mathrm{Ti}$ enhanced the efficiency of PSII that could enhance the photosynthesis by improving the energy transport from PSII to PSI under both conditions (NL and SC).

Soluble sugar content is the direct expression of the strong photosynthesis. Plants translocate sugar from photosynthesizing leaves to storage cells which indicates the physical fitness of the plants (Amiard et al. 2005). In present study, shade had a negative impact on the sugar content of soybean leaves (Fig. 4). Similarly, former studies have reported that cloudy days and low light conditions reduced the soluble sugar content in leaves (Lichtenthaler et al. 1981). However, in this experiment, foliar application of Ti considerably improved the sugar content in plants under SC. Under NL and SC, $\mathrm{T}_{2}$ demonstrated significantly the higher soluble sugar content as compared to $\mathrm{T}_{1}$ and $\mathrm{T}_{0}$ (Fig. 4). Similar results have been reported that titanium oxide improved the soluble sugar content of tomato (Nishizawa et al. 2008) and strawberry (Choi et al. 2015).

Chloroplast ultrastructure controls the photosynthetic performance of crops under changing environmental conditions (Shao et al. 2014). In our study, the number of chloroplasts and grana decreased significantly under shade conditions (Fig. $5 D$ ). The $\mathrm{T}_{1}$ and $\mathrm{T}_{2}$ treatments improved the chloroplast ultrastructure by increasing the number of chloroplasts, thylakoid granal and stromal lamellae under light and shade conditions, which suggests the beneficial effect of $\mathrm{Ti}$ application on photosynthetic apparatus. Furthermore, the improved structure of chloroplasts by $\mathrm{Ti}$ applications suggested that it might develop the shade-tolerant mechanism in soybean plants, especially under shade conditions, such as intercropping and relay intercropping. Carvajal et al. (1994) proposed that $\mathrm{Ti}$ increased iron activity in cell chloroplast and cytoplasm and resulted in increasing plant photosynthetic activity.

It was reported that $\mathrm{Ti}$ application increased the effectiveness of iron in chloroplasts where most of photosynthetic activity occurs (Jaberzadeh et al. 2013).

The total $\mathrm{Ti}$ accumulation by soybean plants increased by applying $\mathrm{Ti}$ at the rate of $25 \mathrm{mg} \mathrm{L}^{-1}\left(\mathrm{~T}_{2}\right)$ in $\mathrm{NL}$, however, the level of accumulation varied between light and shade conditions (Fig. 6D). Our results are similar with previous findings that $\mathrm{Ti}$ accumulation in plants increased with increasing concentration of $\mathrm{Ti}$, e.g., tomato plant accumulated 40 to $50 \mathrm{mg}(\mathrm{Ti}) \mathrm{kg}^{-1}$ (Raliya et al. 2015). In addition, Ti distribution in different plant parts was considerably changed under both conditions. The Ti content in leaves, stems, and roots of soybean plants was significantly higher under NL than that at SC. In support of our findings, previous study found distinct Ti distribution in different plant organs under different light environments (Conway et al. 2015).

Conclusion: Through foliar application, Ti can enter into plant cells by gas-uptake mechanisms and alleviate the detrimental effect of shade stress on plants. Ti improves 


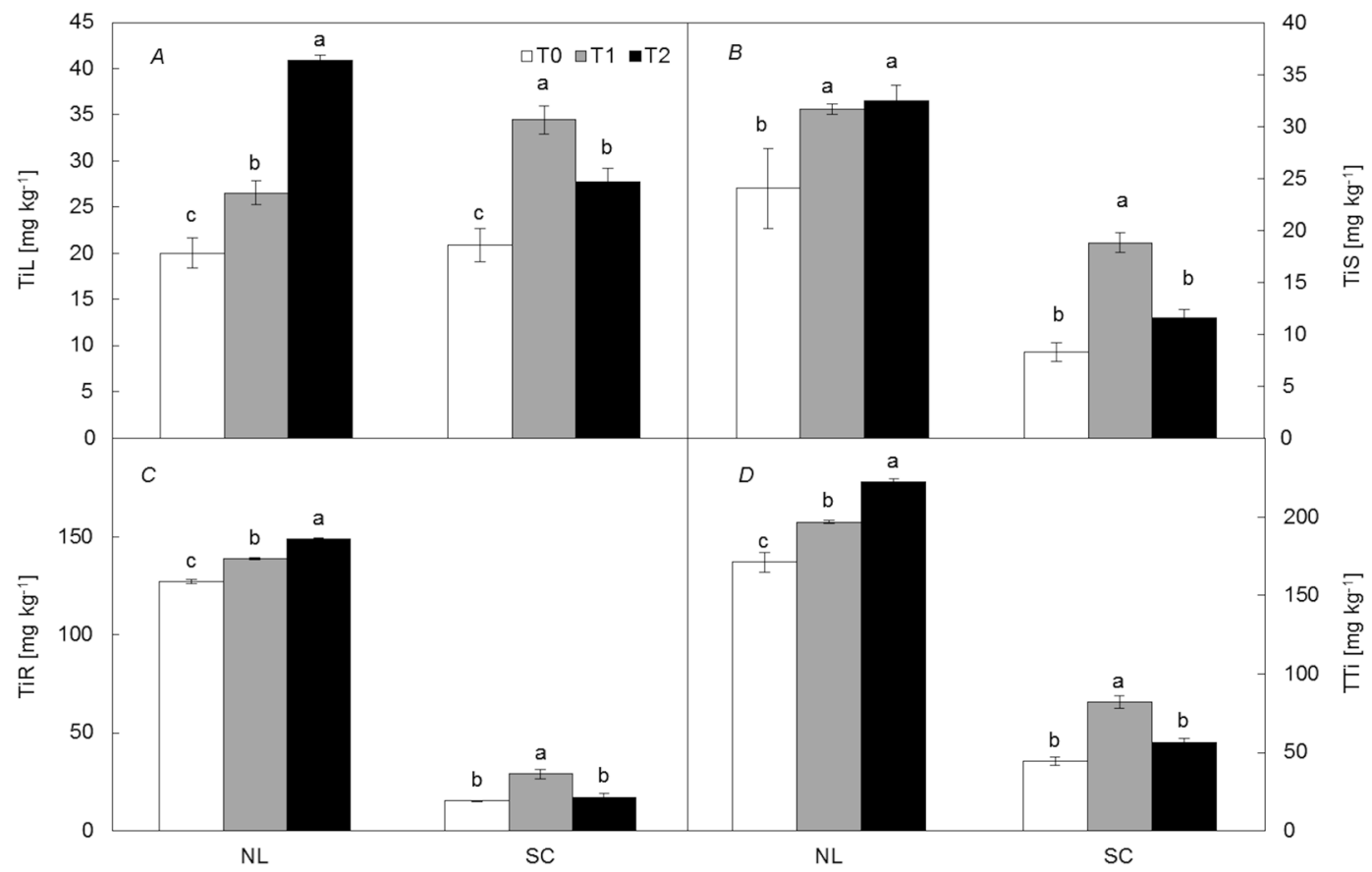

Fig. 6. Titanium accumulation in soybean plants treated with $0 \mathrm{mg}(\mathrm{Ti}) \mathrm{L}^{-1}\left(\mathrm{~T}_{0}\right) ; 12,5 \mathrm{mg}(\mathrm{Ti}) \mathrm{L}^{-1}\left(\mathrm{~T}_{1}\right)$; and $25 \mathrm{mg}(\mathrm{Ti}) \mathrm{L}^{-1}\left(\mathrm{~T}_{2}\right)$ under normal light (NL) and shade conditions $(\mathrm{SC})$. TiL $(A)$, TiS $(B)$, TiR $(C)$, and TTi $(D)$ represent the Ti uptake in leaves, stem, roots, and total titanium accumulation in soybean plants, respectively. Values are means $\pm \mathrm{SE}, n=3$. Different lowercase letters indicate a significant difference $(p<0.05)$ between treatments.

photosynthesis through increasing leaf area, Chl content, Chl fluorescence parameters, such as improving efficiency of $\Phi_{(\mathrm{P})}, \Phi_{(\mathrm{f}, \mathrm{D})}, \mathrm{q}_{\mathrm{p}}$, and $\Phi_{(\mathrm{NPQ})}$, chloroplast structure, and soluble sugar content under NL and SC. Once the Ti ions are acquired, they are distributed through the entire plant by the vascular network. In order to further explore the mode of $\mathrm{Ti}$ action under shade stress, it would be necessary to examine the activity of key enzymes in photosynthesis and their gene expression. Furthermore, bioaccumulation of $\mathrm{Ti}$ may affect the edible parts of soybean plants. Therefore, fundamental research with respect to Ti-plant interaction and seed quality are needed to ensure its precise application in agriculture.

\section{References}

Amiard V., Mueh K.E., Demmig-Adams B. et al.: Anatomical and photosynthetic acclimation to the light environment in species with differing mechanisms of phloem loading. - P. Natl. Acad. Sci. USA 102: 12968-12973, 2005.

Bielczynski L.W., Łącki M.K., Hoefnagels I. et al.: Leaf and plant age affects photosynthetic performance and photoprotective capacity. - Plant Physiol. 175: 1634-1648, 2017.

Buettner K.M., Collins J.M., Valentine A.M.: Titanium(IV) and Vitamin C: Aqueous Complexes of a Bioactive Form of Ti(IV). - Inorg. Chem. 51: 11030-11039, 2012.

Choi H.G., Moon B.Y., Bekhzod K. et al.: Effects of foliar fertilization containing titanium dioxide on growth, yield and quality of strawberries during cultivation. - Hortic. Environ. Biote. 56: 575-581, 2015

Conway J.R., Beaulieu A.L., Beaulieu N.L. et al.: Environmental stresses increase photosynthetic disruption by metal oxide nanomaterials in a soil-grown plant. - ACS Nano 9: 11737$11749,2015$.

Dai Y.J., Shen Z.G., Liu Y. et al.: Effects of shade treatments on the photosynthetic capacity, chlorophyll fluorescence, and chlorophyll content of Tetrastigma hemsleyanum Diels et Gilg. - Environ. Exp. Bot. 65: 177-182, 2009.

Feizi H., Kamali M., Jafari L., Rezvani Moghaddam P.: Phytotoxicity and stimulatory impacts of nanosized and bulk titanium dioxide on fennel (Foeniculum vulgare Mill). Chemosphere 91: 506-511, 2013.

Fu C., Dan L., Chen Y., Tang J.: Trends of the sunshine duration and diffuse radiation percentage on sunny days in urban agglomerations of China during 1960-2005. - J. Environ. Sci. 34: 206-211, 2015.

Hu L., Liao W., Dawuda M.M. et al.: Appropriate $\mathrm{NH}_{4}{ }^{+}: \mathrm{NO}_{3}$ ratio improves low light tolerance of mini Chinese cabbage seedlings. - BMC Plant Biol. 17: doi: 10.1186/s12870-0170976-8, 2017.

Huang D., Wu L., Chen J.R., Dong L.: Morphological plasticity, photosynthesis and chlorophyll fluorescence of Athyrium pachyphlebium at different shade levels. - Photosynthetica 49: 611-618, 2011.

Humplík J.F., Lazár D., Fürst T. et al.: Automated integrative high-throughput phenotyping of plant shoots: a case study of the cold-tolerance of pea (Pisum sativum L.). - Plant Methods 11: doi: 10.1186/s13007-015-0063-9, 2015.

Jaberzadeh A., Moaveni P., Tohidi Moghadam H.R., Zahedi H.: Influence of bulk and nanoparticles titanium foliar application on some agronomic traits, seed gluten and starch contents of wheat subjected to water deficit stress. - Not. Bot. Horti. Agrobo. 41: doi: 10.15835/nbha4119093, 2013.

Lazár D.: Parameters of photosynthetic energy partitioning. - 
J. Plant Physiol. 175: 131-147, 2015.

Lichtenthaler H.K., Bushchmann C., Döll M. et al.: Photosynthetic activity, chloroplast ultrastructure, and leaf characteristics of high-light and low-light plants and of sun and shade leaves. Photosynth. Res. 2: 115-141, 1981.

Ludlow M.M., Wilson G.L., Heslehurst M.R.: Studies on the productivity of tropical pasture plants. V.* Effect of shading on growth, photosynthesis and respiration in two grasses and two legumes. - Aust. J. Agr. Res. 25: 425-433, 1974.

Lyu S., Wei X., Chen J. et al.: Titanium as a beneficial element for crop production. - Front. Plant Sci. 8: doi: 10.3389/ fpls.2017.00597, 2017.

Menglu R., Weiguo L., Xiaoming L. et al.: Effect of shading signal growth and photosynthesis characteristics of soybean seedlings. - Chinese J. Ecol. Agric. 4: 499-505, 2016. [In Chinese]

Nishizawa T., Takeda M., Murayama H., Matsushima, U.: Effects of $\mathrm{TiO}_{2}$ photocatalytic oxidation in the room atmosphere and the quality of tomato fruit during storage under a closed system. - Acta Hortic. 804: 309-314, 2008.

Qu M., Zheng G., Hamdani S. et al.: Leaf photosynthetic parameters related to biomass accumulation in a global rice diversity survey. - Plant Physiol. 175: 248-258, 2017.

Raliya R., Nair R., Chavalmane S. et al.: Mechanistic evaluation of translocation and physiological impact of titanium dioxide and zinc oxide nanoparticles on the tomato (Solanum lycopersicum L.) plant. - Metallomics 7: 1584-1594, 2015.

Raza, M.A., Feng, L.Y., Manaf, A. et al.: Sulphur application increases seed yield and oil content in sesame seeds under rainfed conditions. - Field Crop. Res. 218: 51-58, 2018.

Ren B., Liu W., Zhang J. et al.: Effects of plant density on the photosynthetic and chloroplast characteristics of maize under high-yielding conditions. - Sci. Nat. 104: doi: 10.1007/ s00114-017-1445-9, 2017.

Ruffini Castiglione M., Giorgetti L., Bellani L. et al.: Root responses to different types of $\mathrm{TiO}_{2}$ nanoparticles and bulk counterpart in plant model system Vicia faba L. - Environ. Exp. Bot. 130: 11-21, 2016.

Ruffini Castiglione M., Giorgetti L., Geri C., Cremonini R.: The effects of nano- $\mathrm{TiO}_{2}$ on seed germination, development and mitosis of root tip cells of Vicia narbonensis L. and Zea mays L. - J. Nanopart. Res. 13: 2443-2449, 2011.

Servin A.D., Morales M.I., Castillo-Michel H. et al.: Synchrotron verification of $\mathrm{TiO}_{2}$ accumulation in cucumber fruit: a possible pathway of $\mathrm{TiO}_{2}$ nanoparticle transfer from soil into the food chain. - Environ. Sci. Technol. 47: 11592-11598, 2013.

Shao Q., Wang H., Guo H. et al.: Effects of shade treatments on photosynthetic characteristics, chloroplast ultrastructure, and physiology of Anoectochilus roxburghii. - PLoS ONE 9: 10.1371/journal.pone.0085996, 2014.

Su B.Y., Song Y.X., Song C. et al.: Growth and photosynthetic responses of soybean seedlings to maize shading in relay intercropping system in Southwest China. - Photosynthetica 52: 332-340, 2014.

Wu Y.S., Yang F., Gong W.Z. et al.: Shade adaptive response and yield analysis of different soybean genotypes in relay intercropping systems. - J. Integr. Agr. 16: 1331-1340, 2017.

Yan Y., Wan Y., Liu W. et al.: Influence of seed treatment with uniconazole powder on soybean growth, photosynthesis, dry matter accumulation after flowering and yield in relay strip intercropping system. - Plant Prod. Sci. 18: 295-301, 2015.

Yao X., Li C., Li S. et al.: Effect of shade on leaf photosynthetic capacity, light-intercepting, electron transfer and energy distribution of soybeans. - Plant Growth Regul. 83: 409-416, 2017.

Zhang X., Shang C., Xiao S.: Continuous method and production device for producing hydrolysis-resistant stable ionic titanium. - US, US 8308840 B2 [P]. 2012. http://europepmc. org/patents/PAT/WO2011032305.

(C) The authors. This is an open access article distributed under the terms of the Creative Commons BY-NC-ND Licence. 